\title{
Composição química e atividade antimicrobiana in vitro do óleo essencial de Eucalyptus cinerea F. Mull. ex Benth., Myrtaceae, extraído em diferentes intervalos de tempo
}

\author{
J. Franco, T. Nakashima*, L. Franco, C. Boller \\ Departamento de Farmácia, Universidade Federal do Paraná, Av. Prefeito Lothário Meissner, 3400, \\ Jardim Botânico, 80210-170, Curitiba, PR, Brasil
}

\begin{abstract}
RESUMO: Eucalyptus cinerea é uma espécie aromática da família Myrtaceae, sendo utilizada como ornamental e que apresenta rendimento em óleo essencial considerável. O objetivo deste trabalho foi à avaliação da composição química e da atividade antimicrobiana deste óleo, e das frações coletadas em diferentes intervalos de tempo. A metodologia empregada para a extração do óleo essencial foi a hidrodestilação com arraste de vapor d'água, em aparelho de Clevenger. A análise da composição química foi procedida por CG/EM e para a determinação da atividade antimicrobiana foi utilizado o método de difusão em ágar frente aos microrganismos Staphylococcus aureus ATCC 6.538, Escherichia coli ATCC 8.739, Staphylococcus epidermidis ATCC 12.228 e Pseudomonas aeruginosa ATCC 9.027 e Candida albicans ATCC 10.231. O rendimento do óleo essencial foi de $6,07 \%(\mathrm{v} / \mathrm{m})$, do qual grande parte foi extraída na primeira hora de hidrodestilação. Também foi observada maior concentração de 1,8-cineol nas frações coletadas em quinze minutos e uma hora. Os principais componentes identificados no óleo essencial de E. cinerea por CG/EM foram: 1,8cineol, $\alpha$-pineno, limoneno e $\alpha$-terpineol. A avaliação de atividade antimicrobiana pelo método de difusão em disco indicou qualitativamente o potencial antimicrobiano do óleo essencial da espécie em questão frente a bactérias Gram-positivas, bactérias Gram-negativas e levedura.
\end{abstract}

Unitermos: Eucalytpus cinerea, óleo essencial, atividade antimicrobiana, composição química.

\begin{abstract}
Chemical composition and antimicrobial in vitro activity of the essential oil Eucalyptus cinerea F. Mull. ex Benth., Myrtaceae, extracted in different time intervals" Eucalyptus cinerea is used as an ornamental plant and shows good concentration of essential oil. The aim of this work is a chemical investigation and analysis of the antimicrobial activity of the essential oil of Eucalyptus cinerea collected at different time's interval. This oil was obtained by hydrodestilation in a Clevenger apparatus, the chemical ivestigation was perfoomed by GC/ MS and the antimicrobial activity was assayed in vitro using the agar diffusion method against Staphylococcus aureus ATCC 6538, Escherichia coli ATCC 8.739, Staphylococcus epidermidis ATCC 12.228, Pseudomonas aeruginosa ATCC 9.027 and Candida albicans ATCC 10.231. The yield of the essential oil was $6.07 \%(\mathrm{v} / \mathrm{w})$ collected in the first hour of hidrodestilation. It was also observed a higher concentration of 1,8-cineole in the fraction collected in a quarter of hour and and one hour. The main components investigated in the essential oils by GC/MS were: 1,8-cineole, $\alpha$-pineno, limoneno and $\alpha$-terpineol. The antimicrobial study using agar diffusion method showed antimicrobial activity of the essential oil against Gram-positive, Gram-negative bacteria and yeast.
\end{abstract}

Keywords: Eucalytpus cinerea, essential oil, antimicrobial activity, chemical investigation.

\section{INTRODUÇÃO}

Nos últimos anos, após o uso excessivo de medicamentos antimicrobianos pela população, houve um grande índice de microrganismos que se tornaram resistentes a terapia convencional. Isso fez com que a pesquisa de novas substâncias úteis para combater infecções, tanto em fontes animais como vegetais, fosse intensificada (Silveira, 1997).

Neste sentido, o uso de plantas medicinais sob formas de extrato e fitofármacos, ganhou importância na terapêutica atual (Nascimento et al., 2000). Entretanto, para que soluções efetivas sejam encontradas, deve-se promover um inter-relacionamento das diferentes áreas do conhecimento, incluindo botânica, microbiologia, fitoquímica e a epidemiologia, por exemplo, evitandose estudos de forma isolada que levariam a resultados ineficientes.

Espécies do gênero Eucalyptus destacam-se no reino vegetal pela sua alta importância, tanto por seu valor econômico como do ponto de vista de suas virtudes medicinais. Sob o primeiro aspecto, pode-se ressaltar a indústria madeireira, que aproveita as qualidades das suas várias espécies para os mais variados fins (Cruz, 1985). No campo medicinal tem-se como exemplo a utilização do óleo essencial extraído das folhas do eucalipto no tratamento de diversas doenças do trato respiratório, desde resfriados até sua ação como agente antituberculósico 
(Oyedeji et al., 1999). Outros estudos mostraram também atividade antimicrobiana e antifúngica ligadas a esse vegetal (Cimanga et al., 2002; Delasquis et al., 2002).

E. cinerea, espécie aromática da família Myrtaceae, de origem australiana e aclimatada no Estado do Paraná é cultivada como planta ornamental. Possui rendimento de óleo essencial superior às demais espécies de eucalipto e, como principal constituinte 1,8-cineol, que caracteriza a atividade medicinal (Cruz, 1985; Fabrowski, 2002). Dentro deste contexto, o presente trabalho visa o estudo da composição química e atividade antimicrobiana deste óleo, coletados em diferentes intervalos de tempo.

\section{MATERIAL E MÉTODOS}

\section{Obtenção do material botânico}

As folhas de E. cinerea F. M., Myrtaceae foram coletadas de planta adulta localizada no Centro Politécnico, Campus da Universidade Federal do Paraná (UFPR), município de Curitiba-PR, no período de janeiro a março de 2004. Foi depositada exsicata no Herbário do Departamento de Botânica do Setor de Ciências Biológicas da UFPR, sob o número 47.741.

\section{Extração do óleo essencial}

O óleo essencial foi obtido por hidrodestilação das folhas secas à temperatura ambiente e ao abrigo da luz, em aparelho de Clevenger modificado (USP XXV, 2002). Foram coletadas amostras de óleo essencial de E. cinerea em diferentes tempos de extração visando acompanhar a variação da composição e da atividade antimicrobiana do mesmo, com prolongamento de extração.

Para tanto, foram utilizados $200 \mathrm{~g}$ de folhas secas e fragmentadas, das quais foram extraídas quatro frações distintas no período de 3 horas: Fração 1: fração de 0 a 15 minutos; Fração 2: fração de 15 minutos a 1 hora; Fração 3: fração de 1 a 2 horas; Fração 4: fração de 2 a 3 horas.

Paralelamente, procedeu-se a extração do óleo essencial no período 3 horas (T). Para análise de rendimento do óleo essencial foram realizados análises em triplicata.

\section{Avaliação da composição química}

As amostras de óleo essencial foram analisadas por cromatografia gasosa acoplada a espectrometria de massa (CG/EM), em cromatógrafo 6890 Agilent e espectrômetro de massa 5973 Agilent, com biblioteca NIST 98. Foi utilizada coluna HP5, com gás de arraste: hélio, fluxo de $0,8 \mathrm{~mL} / \mathrm{min}$, temperatura do injetor: 250 ${ }^{\circ} \mathrm{C}$, temperatura inicial: $40{ }^{\circ} \mathrm{C}$, rampa de aquecimento: $2{ }^{\circ} \mathrm{C} / \mathrm{min}$, temperatura final: $250{ }^{\circ} \mathrm{C}$, temperatura do auxiliar: $280{ }^{\circ} \mathrm{C}$, amostras diluídas em $1 \mathrm{~mL}$ de etanol e volume injetado $20 \mu \mathrm{L}$ na razão de Split 100:1 e tempo total de análise de 58 minutos.

\section{Avaliação da atividade antimicrobiana}

\section{Microrganismos utilizados}

Foram utilizados os seguintes microrganismos: Staphylococcus aureus ATCC 6.538, Escherichia coli ATCC 8.739, S. epidermidis ATCC 12.228, Pseudomonas aeruginosa ATCC 9.027 e Candida albicans ATCC 10.231 (NEWPROV $^{\circledR}$ ), sendo estas reconstituídas de acordo com a indicação do fornecedor.

As culturas microbianas foram padronizadas em $10^{8}$ células $/ \mathrm{mL}$, estimadas por comparação ao tubo 0,5 da Escala de McFarland, sendo posteriormente inoculadas em meios de cultura para avaliação da atividade antimicrobiana (Koneman et al., 1997).

\section{Avaliação da atividade antimicrobiana por difusão em ágar}

A atividade antimicrobiana das diferentes frações do óleo essencial de E. cinerea foi realizada de acordo com a metodologia de difusão em disco (Koneman et al., 1997). Nessa técnica, realizada em cabine de segurança biológica Classe II, foram utilizados discos de papel estéreis de 6 mm de diâmetro impregnados com $10 \mu \mathrm{L}$ das frações do óleo essencial de $E$. cinerea, anteriormente esterilizadas em filtro de 0,22 $\mu \mathrm{m}$ (MILLEX $\left.{ }^{\circledR}\right)$. Depois de preparados, os discos foram depositados em ágar Müeller-Hinton para bactérias, utilizando como padrão positivo discos de gentamicina $10 \mu \mathrm{g}\left(\mathrm{NEWPROV}^{\circledR}\right)$ e em ágar Sabouraud tendo como padrão positivo discos de anfotericina B 12,5 $\mu$ g (CRISTÁLIA ${ }^{\circledR}$ ) previamente inoculados com suspensão microbiana. Estes testes foram realizados em triplicata, sendo as placas incubadas a 35 ${ }^{\circ} \mathrm{C} \pm 1$ por 24 horas para as bactérias e $24{ }^{\circ} \mathrm{C} \pm 1,5$ dias para a levedura. Os resultados foram obtidos por meio da observação quantitativa de halos de inibição.

\section{RESULTADOS}

\section{Rendimento do óleo essencial e frações}

A Tabela 1 indica o rendimento do óleo essencial de $E$. cinerea total coletado e também as percentagens colhidas nos tempos pré-estabelecidos (F1: 0-15 minutos; F2: 15 minutos - 1 hora; F3: 1 - 2 horas e F4: 2 - 3 horas).

\section{Composição química do óleo essencial e suas frações}

A Tabela 2 apresenta os resultados da análise da composição química, feita por CG/EM, do óleo essencial de $E$. cinerea e suas frações obtidas por hidrodestilação.

\section{Avaliação da atividade antimicrobiana}

A Tabela 3 apresenta os valores dos halos de 
Tabela 1. Rendimento de óleo essencial de E. cinerea.

\begin{tabular}{ccc}
\hline Amostra & $\begin{array}{c}\text { Rendimento de óleo essencial } \\
(\mathrm{mL} / 100 \mathrm{~g})\end{array}$ & $\begin{array}{c}\text { Rendimento de óleo essencial de cada } \\
\text { fração (\%) }\end{array}$ \\
\hline F1 & $3,02 \pm 0,08$ & 49,75 \\
F2 & $2,19 \pm 0,36$ & 36,08 \\
F3 & $0,58 \pm 0,06$ & 9,56 \\
F4 & $0,28 \pm 0,13$ & 4,61 \\
T & $6,07 \pm 0,26$ & 100 \\
\hline
\end{tabular}

Os valores de F1, F2, F3 e F4 indicam a percentagem média de óleo essencial extraídos nos tempos pré-determinados.

Tabela 2. Componentes do óleo essencial total e frações extraído das folhas de E. cinerea

\begin{tabular}{|c|c|c|c|c|c|}
\hline \multirow{2}{*}{ Prováveis Compostos } & $\mathbf{T}$ & F1 & $\mathbf{F} 2$ & F3 & F4 \\
\hline & $\%$ & $\%$ & $\%$ & $\%$ & $\%$ \\
\hline$\alpha$-Pineno & 6,21 & 2,69 & 3,63 & 6,34 & 9,96 \\
\hline m-Cimeno & $* * *$ & $* * *$ & $* * *$ & $* * *$ & 1,35 \\
\hline Limoneno & $* * *$ & 0,63 & 0,78 & 1,19 & 10,98 \\
\hline 1,8-Cineol & 75,70 & 93,30 & 84,04 & 52,71 & 6,18 \\
\hline 3-Ciclohexen-1-ol & $* * *$ & $* * *$ & $* * *$ & 0,84 & $* * *$ \\
\hline$\alpha$-Terpineol & 9,67 & 1,15 & 4,59 & 15,44 & 20,40 \\
\hline Não identificado & $* * *$ & $* * *$ & $* * *$ & $* * *$ & 3,07 \\
\hline 4-Careno & $* * *$ & 2,23 & $* * *$ & $* * *$ & $* * *$ \\
\hline Ocimeno & 8,42 & $* * *$ & 6,96 & 23,74 & 34,28 \\
\hline Cariofileno & $* * *$ & $* * *$ & $* * *$ & $* * *$ & 3,26 \\
\hline Ledol & $* * *$ & $* * *$ & $* * *$ & $* * *$ & 2,42 \\
\hline 1,3,5-Trimetiladamantano & $* * *$ & $* * *$ & $* * *$ & $* * *$ & 1,89 \\
\hline Não identificado & $* * *$ & $* * *$ & $* * *$ & $* * *$ & 2,31 \\
\hline Não identificado & $* * *$ & $* * *$ & $* * *$ & $* * *$ & 3,90 \\
\hline
\end{tabular}

*** Composto não presente na amostra

Amostras: T (óleo essencial total); F1 (fração coletada no intervalo de 0 a 15 minutos de hidrodestilação); F2 (fração coletada no intervalo de 15 minutos a 1 hora de hidrodestilação); F3 (fração coletada no intervalo de 1 a 2 horas de hidrodestilação) e F4 (fração coletada no intervalo de 2 a 3 horas de hidrodestilação).

Tabela 3. Atividade antimicrobiana do óleo essencial de E. cinerea.

\begin{tabular}{|c|c|c|c|c|c|}
\hline \multirow{2}{*}{$\begin{array}{c}\text { Amostra } \\
10 \mu \mathrm{l}\end{array}$} & \multicolumn{5}{|c|}{ Microrganismos testados } \\
\hline & $\begin{array}{c}\text { S. aureus } \\
\text { ATCC } 6.538\end{array}$ & $\begin{array}{c}\text { E. coli } \\
\text { ATCC } 8.739\end{array}$ & $\begin{array}{l}\text { S. epidermidis } \\
\text { ATCC } 12.228\end{array}$ & $\begin{array}{c}\text { P. aeruginosa } \\
\text { ATCC } 9.027\end{array}$ & $\begin{array}{c}\text { C. albicans } \\
\text { ATCC } 10.231\end{array}$ \\
\hline $\mathrm{F} 1$ & 8 & 7 & 9 & 10 & 7 \\
\hline $\mathrm{F} 2$ & 9 & 10 & 14 & 11 & 9 \\
\hline F3 & 19 & 11 & 21 & 14 & 15 \\
\hline $\mathrm{F} 4$ & 17 & 10 & 20 & 13 & 14 \\
\hline $\mathrm{T}$ & 15 & 8 & 16 & 9 & 8 \\
\hline Genta. $10 \mu \mathrm{g}$ & 23 & 26 & 27 & 26 & - \\
\hline Anf.B12,5 $\mu \mathrm{g}$ & - & - & - & - & 15 \\
\hline
\end{tabular}

Os resultados representam à média dos diâmetros dos halos de inibição em milímetros (mm). 
inibição (mm) observados para as amostras do óleo essencial e suas frações obtidos por hidrodestilação, em aparelho de Clevenger, das folhas de E. cinerea frente aos microrganismos $S$. aureus ATCC 6.538, E. coli ATCC 8.739, S. epidermidis ATCC 12.228, P. aeruginosa ATCC 9.027 e C. albicans ATCC 10.23. Discos impregnados com $10 \mu \mathrm{g}$ de gentamicina e $12,5 \mu \mathrm{g}$ de anfotericina B foram utilizados como controle positivo.

\section{DISCUSSÃO}

$\mathrm{O}$ rendimento do óleo essencial coletado em três horas de hidrodestilação foi de 6,07 \% (v/m). Foi observado que grande parte do óleo essencial é extraída no início da destilação, mantendo os níveis de rendimento satisfatório na primeira hora de extração, diminuindo-se consideravelmente até a última fração F4 (3 horas de hidrodestilação).

A análise da composição do óleo essencial de E. cinerea total (T) e frações (F1-F4) demonstrou, por meio de cromatografia gasosa acoplada a espectrometria de massa, predominância dos compostos 1,8-cineol nas frações F1-F3, seguidos por $\alpha$-pineno em F1 (15 minutos de extração) e $\alpha$-terpineol em F2 e F3 (1 hora e 2 horas de extração, respectivamente). Em F4 houve a predominância de ocimeno, seguido por $\alpha$-terpineol, limoneno e $\alpha$-pineno. A maior ocorrência de 1,8-cineol no início da extração é justificada pela maior rapidez de extração de compostos oxigenados (Prins et al., 2003) e pelo seu ponto de ebulição (The Merck Index, 1996).

O óleo essencial de E. cinerea total coletado (T) e as frações (F1, F2, F3 e F4) apresentaram halo de inibição frente a todos os microrganismos testados nesta avaliação. O controle de qualidade do método em detectar a inibição bacteriana e fúngica foi avaliado utilizandose antibióticos com diâmetros de halo conhecidos. Os valores especificados na tabela 3 estão de acordo com o preconizado para cada espécie (Isenberg, 1992).

Observa-se atividade em todas as amostras testadas, sendo que as frações do óleo essencial obtidas nas últimas coletas apresentam maior halo de inibição frente aos microrganismos testados, não necessariamente condizendo com maior atividade antibiótica deste. Esta observação é explicada devido às propriedades físico-químicas dos componentes de cada amostra que podem influenciar na melhor difusão no meio de cultura (Janssen et al., 1987; Koneman et al., 1997). Por meio desta técnica, podem-se comparar resultados somente de mesma amostra (Williams, 1996).

\section{REFERÊNCIAS}

Cimanga K, Kambu K, Tona L, Apers S, Bruyne T, Hermans N, Totté J, Pieters L, Vlietinck AJ 2002. Correlation between chemical composition and antibacterial activity of essential oils of some aromatic medicinal plants growing in the Democratic Republic of Congo.
J Ethnopharmacol 79: 213-220.

Cruz GL 1985. Dicionário das plantas úteis do Brasil. 3.ed. Rio de Janeiro: Civilização brasileira.

Delasquis PJ, Stanich K, Girard B, Mazza G 2002. Antimicrobial activity of individual and mixed fractions of dill, cilandro, coriander and eucalyptus essential oils. Food Microbiol 74: 101-109.

Fabrowski FJ 2002. Eucaliptus smithii R. T. Baker (Myrtaceae) como espécie produtora de óleo essencial no sul do Brasil. Curitiba, 225 p. Tese (Doutorado em Engenharia Florestal) - Centro de Ciências Agrárias, Universidade Federal do Paraná.

Isenberg HD 1992. Clinical microbiology procedures handbook. v.1. Washington, D.C: American Society for Microbiology.

Janssen AM, Scheffer JJC, Swendsen AB 1987. Antimicrobial activity of essential oils: A 1976-1986 literature review. Aspects of the tests methods. Planta Med 53: 395-398.

Koneman EW, Allen SD, Janda WN, Schreckenberger PC, Winn Jr WC 1997. Antimicrobial susceptibility testing. In: Color atlas and text book of diagnostic microbiology. 5.ed. Philadelphia- New York: Lippncott.

Nascimento GGF, Locatelli J, Freitas PC, Silva GL 2000. Antibacterial activity of plant extracts and phytochemicals on antibiotic-resistant bactéria. Braz J Microbiol 31: 247-256.

Oyedeji AO, Ekundayo O, Olawore O, Adeniyi BA, Koenig WA 1999. Antimicrobial activity of the essencial oils of five Eucalyptus species growing in Nigeria. Fitoterapia 70: 526-528.

Prins CL, Lemos GCS, Freitas SP 2003. Efeito do tempo de extração sobre a composição e o rendimento do óleo essencial de alecrim (Rosmarinus officinalis). In: Anais do II Simpósio Brasileiro de Óleos Essenciais, Campinas, p.99.

Silveira F 1997. Avaliação da atividade antimicrobiana de extratos vegetais. Curitiba, 26p. Monografia (Especialização em Ciências Farmacêuticas - Produtos Naturais), Setor de Ciências da Saúde, Universidade Federal do Paraná.

The Merck Index 1996. An encyclopedia of chemicals, drugs and biologycals. 12 ed. Rahway.

The United States Pharmacopeia 2002. 25 $5^{\text {th }}$ ed. Rockville: United States Pharmacopeial Convention.

Williams L 1996. Ranking antimicrobial activity. Int $J$ Aromatherapy 7: 32-35. 